Journal of Zhejiang University-SCIENCE C (Computers \& Electronics)

ISSN 1869-1951 (Print); ISSN 1869-196X (Online)

www.zju.edu.cn/jzus; www.springerlink.com

E-mail: jzus@zju.edu.cn

\title{
Erratum:
}

\section{Erratum to: Optimization of the resonant frequency servo loop technique in the resonator micro optic gyro}

\author{
Yang $\mathrm{REN}^{\dagger}$, Zhong-he JIN ${ }^{\dagger}$, Yan CHEN, Hui-lian MA \\ (Department of Information Science \& Electronic Engineering, Zhejiang University, Hangzhou 310027, China) \\ †E-mail: zju.renyang@qq.com; jinzh@zju.edu.cn
}

doi:10.1631/jzus.C10e0441

Erratum to: J Zhejiang Univ-Sci C (Comput \& Electron) 2011 12(11):942-950 doi:10.1631/jzus.C1000441

The original version of this article unfortunately contained a mistake. The disclosure of financial support should be disregarded. 